\title{
Research on Maximum Power Point Algorithm Based on Adaptive Duty Cycle
}

\author{
Suting Liang ${ }^{1,2}$, Lei Zhao ${ }^{1,2}$, Wenjing Wang ${ }^{1,2}$ \\ ${ }^{1}$ Institute of Electrical Engineering, Chinese Academy of Sciences, Beijing, China \\ ${ }^{2}$ University of Chinese Academy of Sciences, Beijing, China
}

Email address:

liangst005@mail.iee.ac.cn (Suting Liang), zhaolei@mail.iee.ac.cn (Lei Zhao),wangwj@mail.iee.ac.cn (Wenjing Wang)

\section{To cite this article:}

Suting Liang, Lei Zhao, Wenjing Wang. Research on Maximum Power Point Algorithm Based on Adaptive Duty Cycle. Journal of Electrical and Electronic Engineering. Vol. 5, No. 6, 2017, pp. 235-241. doi: 10.11648/j.jeee.20170506.14

Received: November 15, 2017; Accepted: November 23, 2017; Published: December 28, 2017

\begin{abstract}
In solar photovoltaic (PV) system it has been a tendency to extract the maximum output power from the PV panel with the decrease of production price. There are many novel control algorithms to track the maximum power point. The commonly used control algorithm is based on perturbation and observation algorithm (P\&O). However, the traditional $\mathrm{P} \& \mathrm{O}$ method has some problems between the tracking speed and the control accuracy. In this paper, the mathematic model of photovoltaic cells is studied and a modified perturbation observation method is proposed. The algorithm adjusts the duty cycle step by step according to the variation of the slope of the power voltage curve. Simulink simulation of the PV module with the buck circuit proves the superiority of the variable duty cycle perturbation method in terms of tracking speed and stability compared with the traditional perturbation observation method.
\end{abstract}

Keywords: Photovoltaic System, Maximum Power Point, Variable Step Size, Adaptive

\section{Introduction}

The renewable energy sources have been widely used due to rising world-wide energy demands and soaring prices of fossil fuels. Main renewable energy sources include solar energy, biomass energy and geothermal energy. Among these, solar energy has developed rapidly in recent years. As prices of the photovoltaic panel decrease, more and more people begin to pay attention to improving the operating efficiency of the PV panel [1]. However, due to the nonlinear relation between the output current and terminal voltage of the photovoltaic cell, maximum power can only be reached when it operates at a certain output voltage. The output power of the PV cell changes with irradiation and temperature. In order to improve the total output power, many novel control algorithms have been proposed to track the maximum power point.

According to the characteristics of maximum power point tracking, MPPT algorithm can be roughly divided into the traditional algorithm and the intelligent algorithm. Among these, traditional algorithm includes perturbation and observation algorithm ( $\mathrm{P} \& \mathrm{O})$, incremental conductance algorithm (IC), constant voltage control, short circuit current method and so on. Intelligent algorithm is mainly about the particle swarm optimization algorithm(PSO) [2], the neural network method (NM) [3] and the fuzzy logic method [4]. Currently intelligent algorithm has not been widely used due to its complex control principle. The commonly used control algorithm is based on perturbation and observation algorithm (P\&O) [5].

The perturbation observation method is also called as a hill climbing method. Its basic principle is to add a disturbance voltage [6]. If the power increase, then keep the disturbance in the same direction and vice versa. At last, working point is near the maximum power point and swing. The advantage of $\mathrm{P} \& \mathrm{O}$ is that its accuracy is higher and the measured parameters are easy to achieve. However, the conventional perturbation observation method has the following disadvantages: the tracking speed and the control accuracy are contradictory, that is to say, the steady oscillation is small when the tracking speed is slow. When the tracking speed is fast, the steady oscillation becomes 
larger. In this paper, aiming at balancing the contradiction between tracking speed and steady oscillation in conventional perturbation observation method, a modified perturbation observation method is proposed. Based on the principles and mathematical models of photovoltaic cells, the PV module and buck circuit model are built in MATLAB/Simulink. Compared with the traditional perturbation observation method in the same simulation environment, the modified perturbation observation method is highly efficient.

\section{Mathematical Models of Photovoltaic Cells}

According to the electronics theory, a solar cell can be represented by an equivalent circuit. There are many equivalent circuits of a solar cell, where the single-diode and two-diode models could be the most widely used. Since the single-diode model is simple and accurate enough in many cases, it is applied in this paper which is shown in Figure 1 [7].

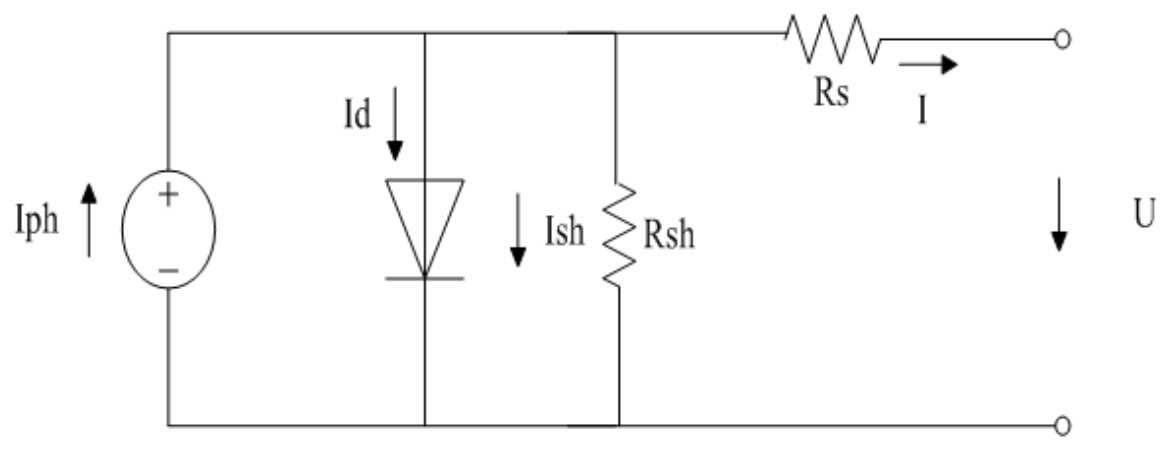

Figure 1. Electrical circuit of a solar cell.

The symbols in Figure 1 are defined as follows:

$I_{p h}:$ photocurrent;

$I_{d}$ : current of parallel diode;

$I_{\text {sh }}:$ shunt current;

I: output current;

$\mathrm{U}$ : output voltage;

$R_{\text {sh }}:$ shunt resistance;

$R_{s}$ : series resistance.

With reference to the equivalent circuit, the relationship between the output voltage and the output current can be expressed as [8]:

$$
I=I_{p h}-I_{o}\left\{\left[\exp \left(\frac{q\left(U+I R_{S}\right)}{n K T}\right)\right]-1\right\}-\frac{U+I R_{S}}{R_{S h}}
$$

Where $I_{o}$ - reverse saturation current of the diode $(\mathrm{A}) ; \mathrm{q}-$ the electron charge $\left(1.602 \times 10^{-19} \mathrm{C}\right)$; K- Boltzmann constant $\left(1.38 \times e^{-23} \mathrm{~J} / \mathrm{K}\right)$; $\mathrm{n}$-the curve fitting factor.

The term $\left(\mathrm{U}+\mathrm{I} R_{s}\right) / R_{s h}$ can be ignored, because it is far less than $I_{p h}$, so the formula can be simplified as:

$$
I=I_{p h}-I_{o}\left\{\left[\exp \left(\frac{q\left(U+I R_{S}\right)}{n K T}\right)\right]-1\right\}
$$

As $I_{p h}, I_{o}, R_{s}$ and $\mathrm{n}$ in formula (2) are difficult to determine and these parameters are not the technical parameters provided by manufacturers, the formula is only for theoretical research. Usually PV model datasheets provide users with the following parameters: short-circuit current $\left(I_{s c}\right)$, open-circuit voltage $\left(U_{o c}\right)$, the maximum power point current $\left(I_{m}\right)$ and the maximum power point voltage $U_{m}$.

In this paper, the actual engineering model combined with the specific parameters of photovoltaic cells which are provided by manufacturers to study the characteristics of PV modules is used. Since the solar irradiation $G$ and the temperature $\mathrm{T}$ are two major factors that affect the photocurrent $I_{p h}$, the photocurrent under certain conditions can be obtained by the following formula. Standard conditions are: $\mathrm{G}_{\text {nom }}=1000 \mathrm{~W} / \mathrm{m}^{2}, T_{1}=25^{\circ} \mathrm{C}$.

$$
\begin{gathered}
I_{p h}=I_{p h(T 1)}[1+k o(T-T 1)] \\
I_{p h(T 1)}=\frac{G I_{s c(T 1)}}{G_{n o m}} \\
k o=\frac{I_{s c(T 2)}-I_{s c(T 1)}}{I_{s c(T 1)}(T 2-T 1)}
\end{gathered}
$$

As the temperature affects the diode's reverse saturation current $I_{o}$, the following equation can be used to find the diode saturation current at a certain temperature:

$$
\begin{gathered}
I_{o}=I_{o(T 1)}\left(\frac{T}{T 1}\right)^{\frac{3}{n}} \exp \left[\frac{-q E_{q}}{n k}\left(\frac{1}{T}-\frac{1}{T 1}\right)\right] \\
I_{o(T 1)}=\frac{I_{s c(T 1)}}{\exp \left[\frac{q U_{o c(T 1)}}{n K T 1}-1\right.}
\end{gathered}
$$

By differentiating the two sides of equation (2) and making $\mathrm{U}=U_{o c}$, then subtracting them, the resistance $R_{S}$ can be obtained. And $\left.\frac{d U}{d I}\right|_{U_{o c}}$ can be obtained from the manufacturer:

$$
\begin{aligned}
& R_{s}=-\left.\frac{d U}{d I}\right|_{U_{o c}}-\frac{1}{X_{v}} \\
& X_{v}=I_{o(T 1)} \frac{q}{n K T 1} \exp \left[\frac{q U_{o c(T 1)}}{n K T 1}\right]
\end{aligned}
$$


Combined the formula (3) - (9) with the related data provided by manufacturers, the PV module is designed using the $\mathrm{M}$ function in MATLAB/Simulink. According to the input voltage $\mathrm{U}$, irradiation $\mathrm{G}$, temperature $\mathrm{T}$, the current $\mathrm{I}$ can be calculated. Thus I-U and P-U curve of the module can be drawn.

\section{Principle Analysis of Adaptive Duty Cycle Disturbance Method}

In this paper, a modified perturbation observation method that can adjust the disturbance step size is proposed. The principle is based on U-P curve of photovoltaic cells [9]:

At the maximum power point (MPP), $\frac{d P}{d U}=0$.

On left side of MPP, $\frac{d P}{d U}>0$.

On right side of MPP, $\frac{d P}{d U}<0$.

The PV module voltage and current (Difference between the present value and previous value) are used to calculate the values of $\mathrm{dU}$ and $\mathrm{dI}$. Also we can get $\mathrm{dP}=\mathrm{dI} * \mathrm{dU}$. If $\left|\frac{d P}{d U}\right|<e$ (e is set as $\tan 1^{\circ}$ or $\tan 2^{\circ}$ ), then the atmospheric conditions have not changed and the MPPT is still operating at the MPP. If $\left|\frac{d P}{d U}\right|>e$, it indicates the operating point is on the left side or right side of MPP. Then we begin to calculate the value of $\Delta \mathrm{U}^{*} \Delta \mathrm{P}$. If $\Delta \mathrm{U}^{*} \Delta \mathrm{P}>0$, it indicates that the operating point is on the left side of MPP. To track the MPP, it is necessary to increase the operating voltage. On the other hand, if $\Delta \mathrm{U}^{*} \Delta \mathrm{P}<0$, the operating voltage should decrease. The operating voltage change in this paper is done by adjusting a step size $\Delta \mathrm{D}\left(\mathrm{b} \frac{d P}{d U}\right)$ to the duty cycle D of a DC-DC converter. The step size can be adjusted itself. When the operating point is far away from the maximum power point, a large step size can be used to improve the tracking speed (at this moment $\mathrm{b} \frac{d P}{d U}$ determines to use a big step size). When it is approaching the maximum power point, $\mathrm{b} \frac{d P}{d U}$ determines to use a small step size to ensure the tracking accuracy. So the modified P\&O method can balance the contradiction between tracking speed and steady oscillation in traditional perturbation observation method. The flow chart of the modified perturbation observation algorithm is shown in Figure 2.

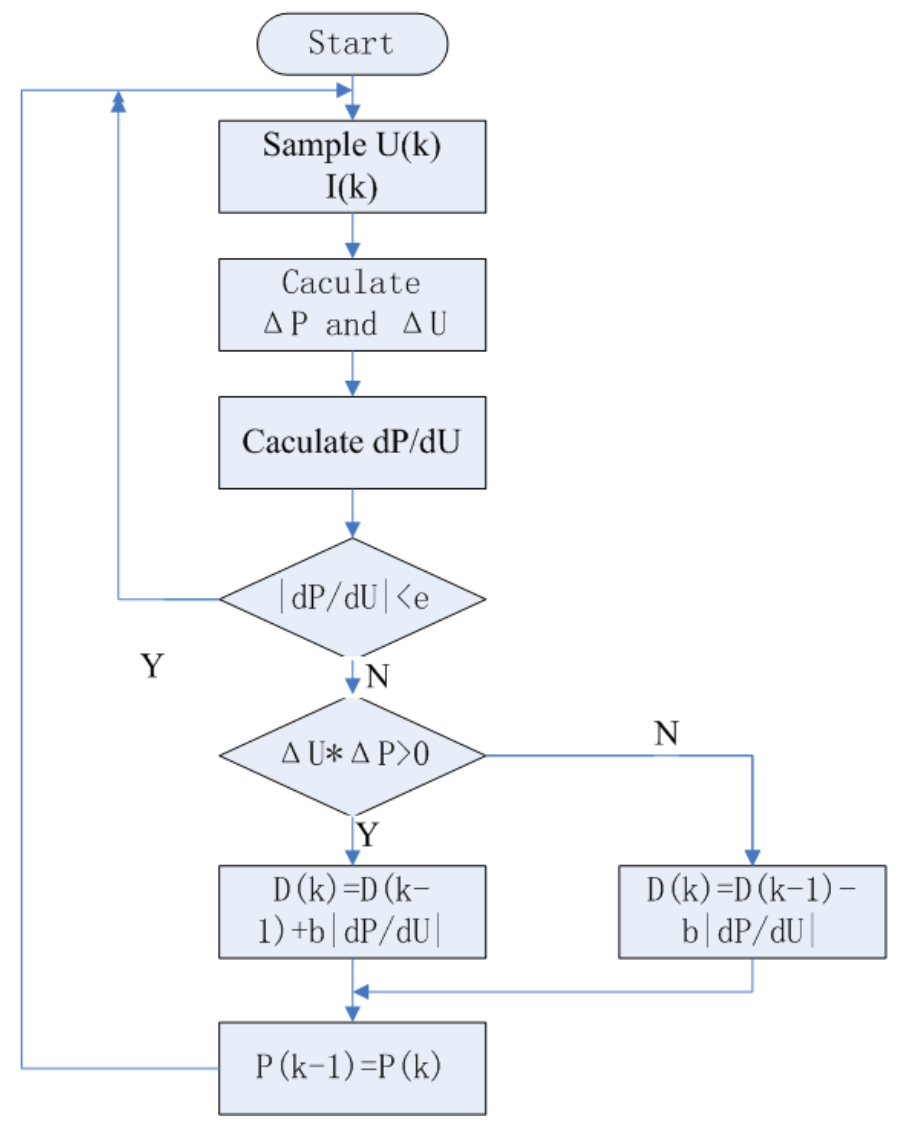

Figure 2. Flow chart for modified $P \& O$.

\section{Photovoltaic System Simulation}

\subsection{Photovoltaic Cell Simulation}

In the MATLAB/Simulink platform, the most commonly used way of building a PV module is to use existing modules of Simulink, but it is very complicated. A large number of sub-modules are not good for researchers to check and set parameters. So in this paper, Matlab Function is used to write the $\mathrm{M}$ function of photovoltaic cell in Matlab R2016b. There 
are three inputs and one output ports in this model, where $\mathrm{G}$ is insolation, $\mathrm{T}$ is temperature of $\mathrm{PV}$ module, $\mathrm{U}$ is output voltage of PV module and I is output current of PV module. A 60W PV module Solarex MSX60 was chosen for modeling. The concerned electrical characteristics specifications are shown in Table 1.

Table 1. Solarex MSX60 60W.

\begin{tabular}{ll}
\hline Maximum power $P_{m}$ & $59.9 \mathrm{~W}$ \\
Current at $P_{\max } I_{m}$ & $3.5 \mathrm{~A}$ \\
Voltage at $P_{\max } U_{m}$ & $17.1 \mathrm{~V}$ \\
Short circuit current $I_{s c}$ & $3.74 \mathrm{~A}$ \\
Open circuit voltage $U_{o c}$ & $21.0 \mathrm{~V}$ \\
Insolation $G_{\text {nom }}$ & $1000 \mathrm{~W} / \mathrm{m}^{2}$ \\
Temperature $T 1$ & $25^{\circ} \mathrm{C}$ \\
\hline
\end{tabular}

Given the PV module to obtain the $I-V$ characteristics of the various insolation. U-I curves and U-P curves of presented model at the same temperature $\left(25^{\circ} \mathrm{C}\right)$ but at different insolation levels are shown in Figure 3 and Figure 4. The insolation is $1000 \mathrm{~W} / \mathrm{m}^{2}, 800 \mathrm{~W} / \mathrm{m}^{2}$ and $600 \mathrm{~W} / \mathrm{m}^{2}$, respectively. Figure 3 and Figure 4 show that the use of equations (3) - (9) to establish the simulation model can correctly reflect the characteristics of photovoltaic cells curve.

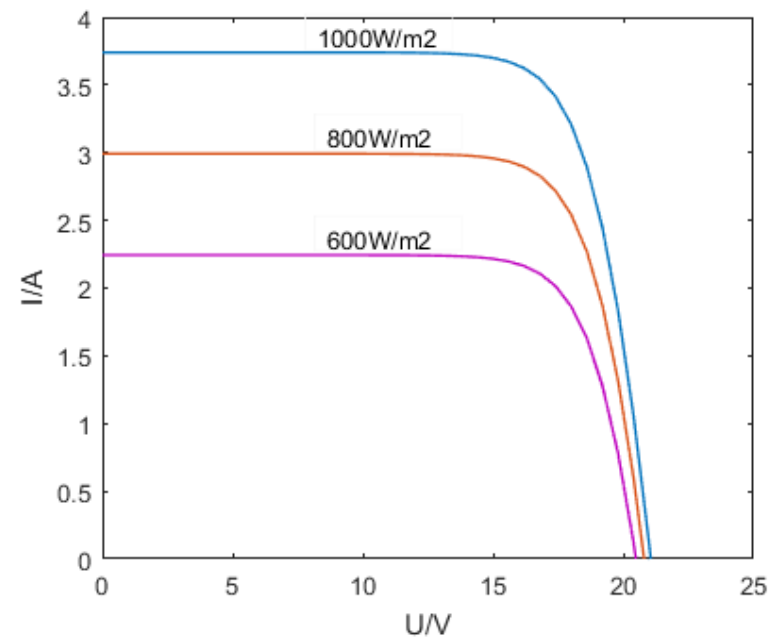

Figure 3. U-I curves of the PV module.

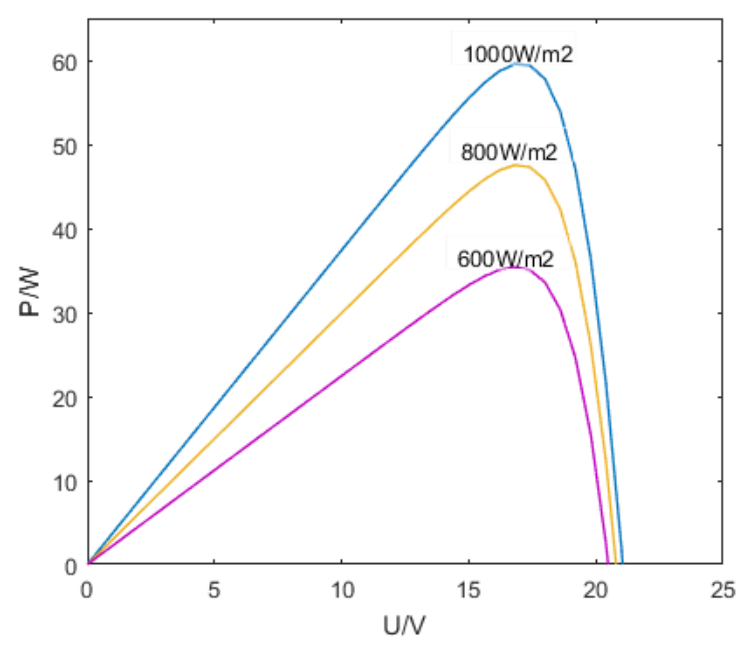

Figure 4. U-P curves of the PV module.

\subsection{Maximum Power Point Tracker}

The maximum power point tracking (MPPT) controller [10] draw maximum available power by forcing the PV module to operate at close to maximum power operation point. Power output from the PV module changes due to changes in solar radiation and temperature. Maximum power point tracker (MPPT) is used with a dc-dc converter (step up/step down) which serves the purpose of transferring maximum power from the solar PV module to the load. The duty cycle of dc-dc converter is changed with the load impedance as well as the source is also changed and matched at the maximum point of power. The duty cycle of the converter is changed till the peak power point is obtained. Consider $U_{o}$ is output voltage and $U_{\text {in }}$ is input voltage, for a buck converter: $U_{o}=D U_{i n}$.

\subsection{Comparation of Traditional $P \& O$ and Modified $P \& O$}

In this paper, a buck converter is chosen for simulation in which the buck circuit is packaged in the sub-module named Subsystem. To meet the simulation accuracy, the circuit selects the input capacitor $\mathrm{C} 1=300 \mathrm{uF}$, inductor $\mathrm{L}=500 \mathrm{uH}$ and the output capacitor $\mathrm{C} 2=300 \mathrm{uF}$. The overall MATLAB/Simulink model is shown in Figure 5.

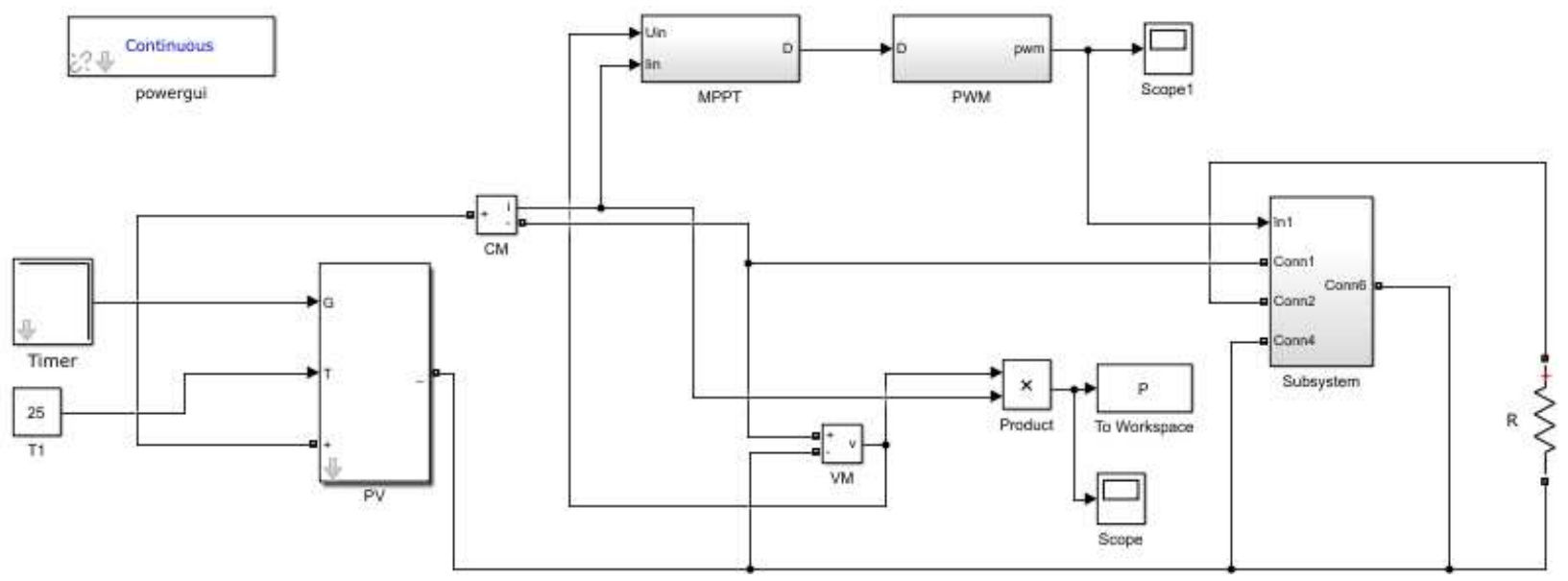

Figure 5. MATLAB/Simulink model of PV model with MPPT. 


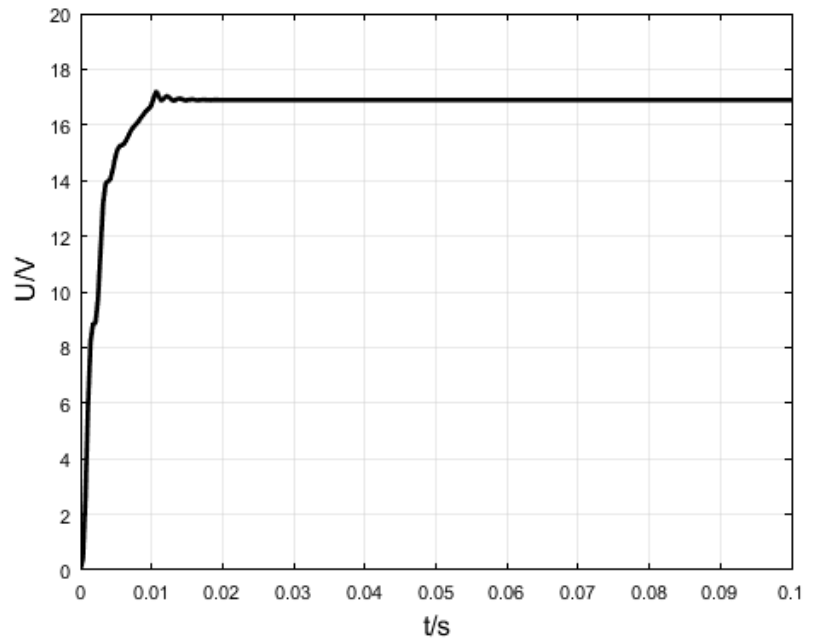

Figure 6. U-t curve of traditional $P \& O(d=0.003)$.

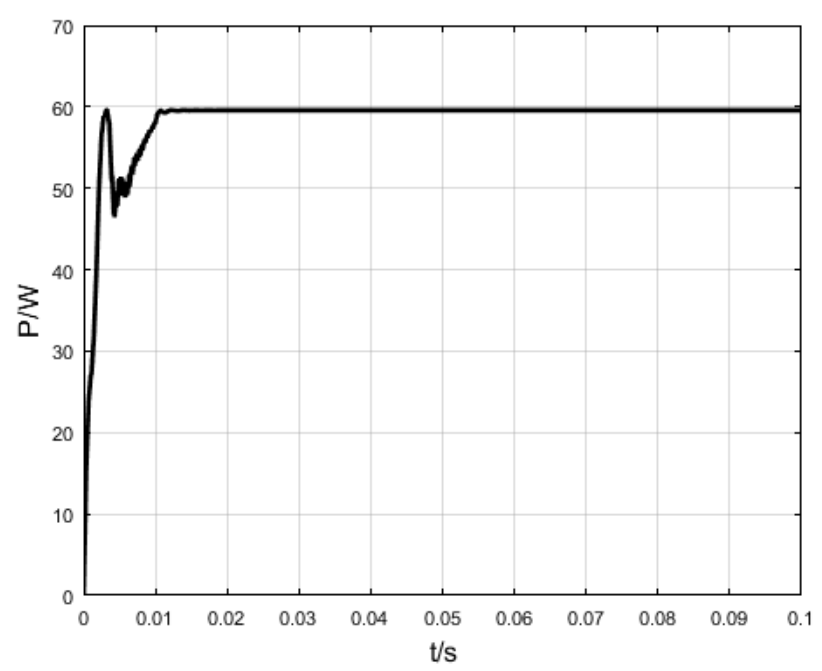

Figure 7. $P$-t curve of traditional $P \& O(d=0.003)$.

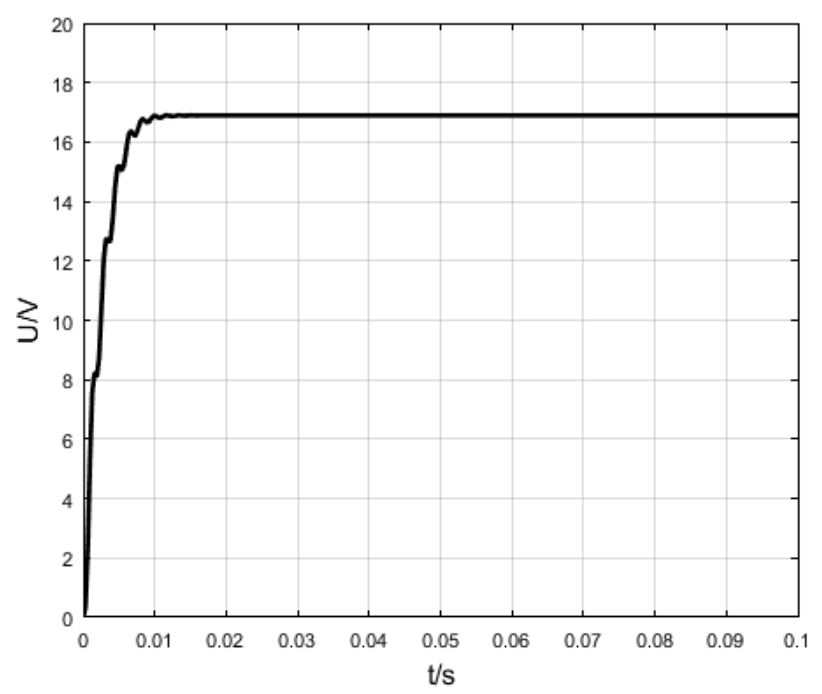

Figure 8. $U$ - $t$ curve of modified $P \& O(b=0.003)$.

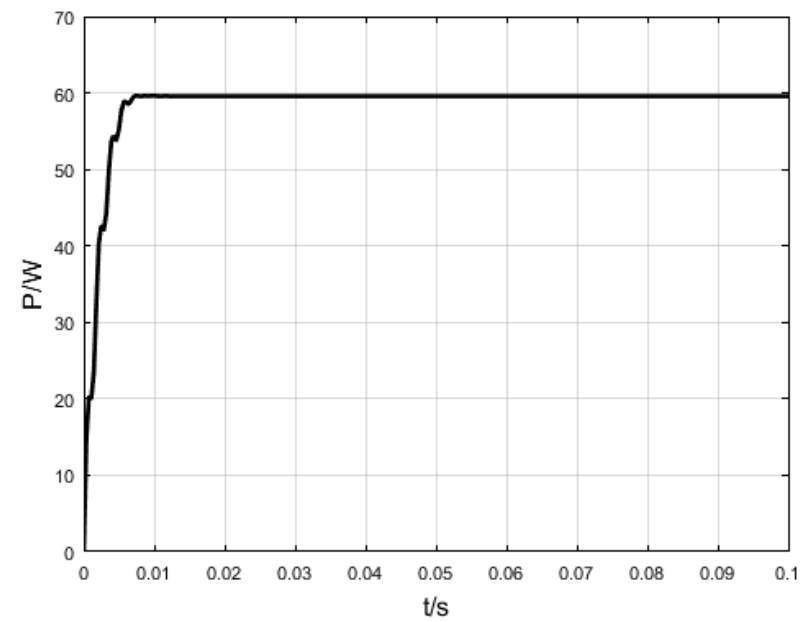

Figure 9. $P$-t curve of modified $P \& O(b=0.003)$.

The traditional perturbation observation method and the modified $\mathrm{P} \& \mathrm{O}$ are simulated in the same conditions. The step size of duty cycle in traditional method is set to 0.003 while $b$ in the modified $\mathrm{P} \& \mathrm{O}$ is also set to 0.003 , the solution method in Simulink is ode $23 \mathrm{tb}$, and the simulation time is $0.1 \mathrm{~s}$. The solar irradiance is $1000 \mathrm{~W} / \mathrm{m}^{2}$ and the temperature is $25^{\circ} \mathrm{C}$. The output voltage and output power of the PV module are shown in Figure 6, Figure 7, Figure 8 and Figure 9.

Figure 6 and Figure 7 show that the conventional perturbation observation need to reach the maximum power point around $60 \mathrm{~W}$ after $0.01 \mathrm{~s}$ and oscillation before reaching a steady value is bigger. Figure 8 and Figure 9 show that the adaptive duty cycle algorithm can reach the maximum power point around $60 \mathrm{~W}$ before $0.01 \mathrm{~s}$. Also it can relatively smooth to achieve the maximum power point.

Under the same conditions, the step size of duty cycle in the traditional perturbation observation method is set as 0.02 while $\mathrm{b}$ in the modified $\mathrm{P} \& \mathrm{O}$ is also set as 0.02 . The output voltage and output power curves of the photovoltaic module can be obtained in Figure 10, Figure 11, Figure 12 and Figure 13.

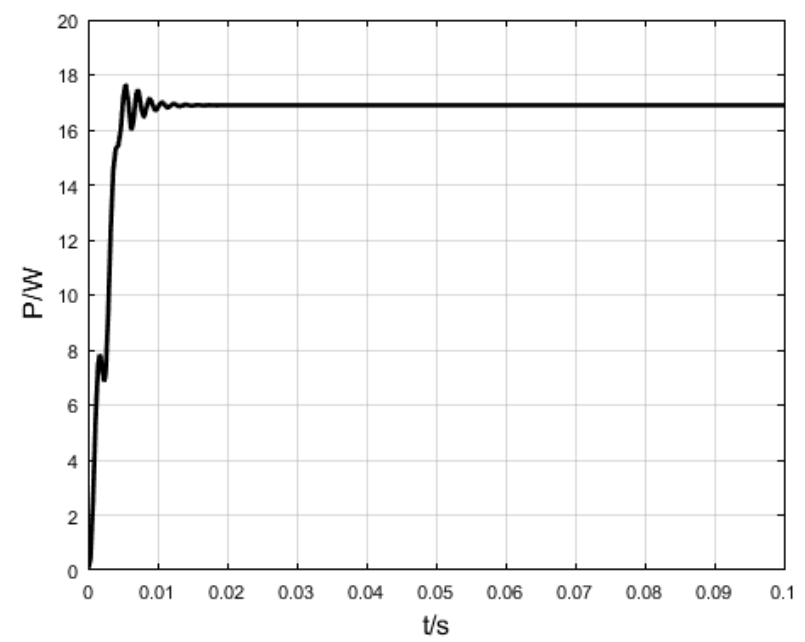

Figure 10. $U$-t curve of traditional $P \& O(d=0.02)$. 


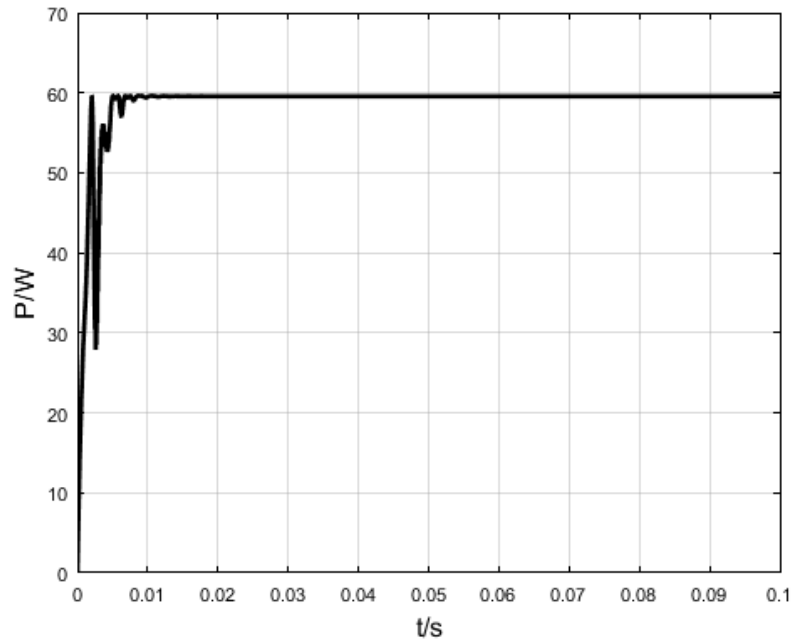

Figure 11. $P$-t curve of traditional $P \& O(d=0.02)$.

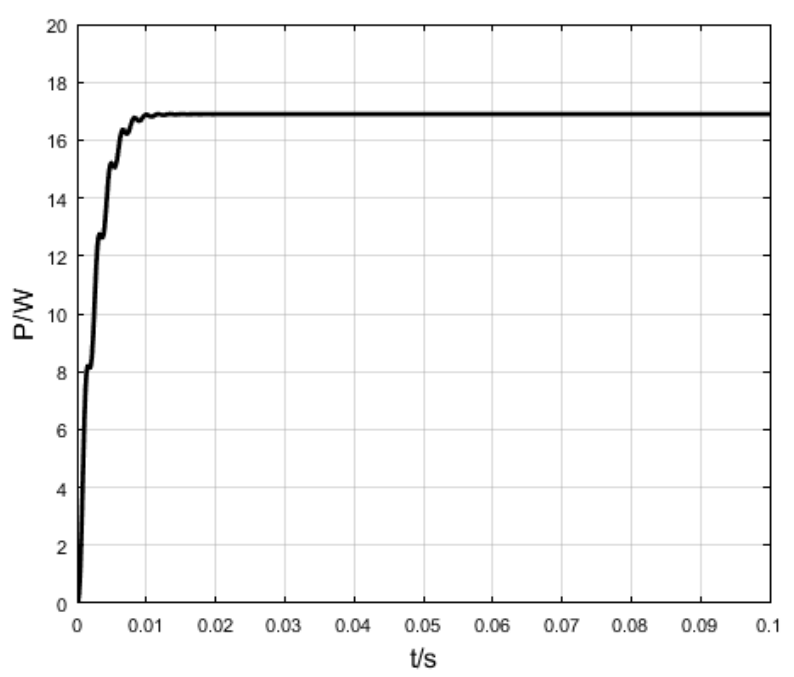

Figure 12. U-t curve of modified $P \& O(b=0.02)$.

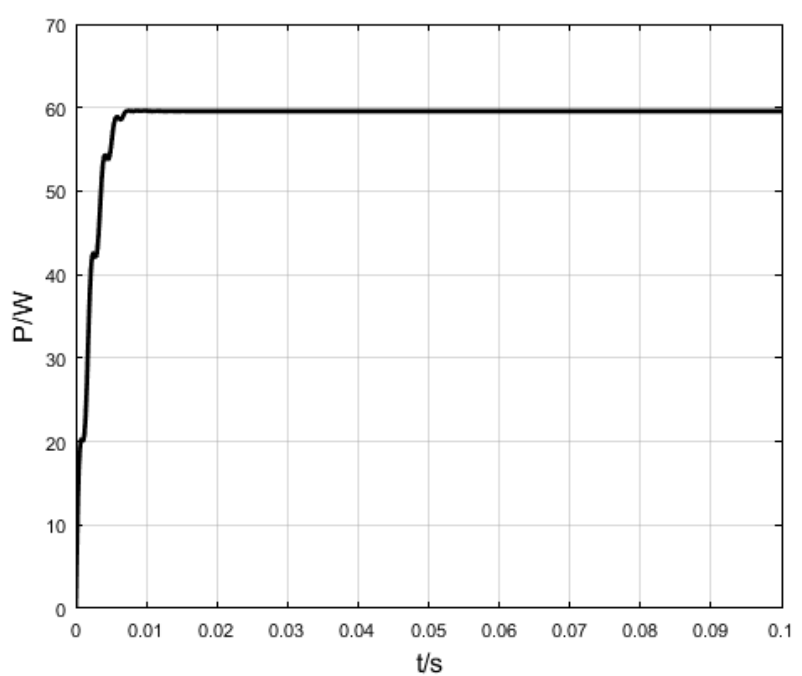

Figure 13. $P$-t curve of modified $P \& O(b=0.02)$.

Figure 10 and Figure 11 show that the oscillations of the output voltage and power curves increase in the traditional perturbation observation method when step size of duty cycle is set to 0.02 in comparision with 0.003 . Meanwhile, the output voltage and power curves of Figure 12 and Figure 13 stay the same. From the above result we come to the conclusion that the modified $\mathrm{P} \& \mathrm{O}$ has faster tracking speed. For traditional perturbation observation method, the increase of the duty cycle step size increases the oscillation before reaching the maximum power point.

\section{Conclusion}

In this paper, the mathematic model of photovoltaic cells is studied. The simulation model of traditional perturbation observation method and the improved perturbation observation method are established in Matlab Simulink. Comparing the output power and voltage of the modified $\mathrm{P} \& \mathrm{O}$ to the traditional method, it is shown that the modified P\&O algorithm can track the maximum power point more quickly, thus ensuring the tracking speed. Meanwhile, with the increase of the duty cycle step size, the oscillation of the U-t and P-t curves in the modified $\mathrm{P} \& \mathrm{O}$ do not significantly increase, effectively improving the stability and reliability of the system. Future work includes implementing this technique.

\section{References}

[1] Hengyang Luo, Huiqing Wen and Xingshuo Li. " Distributed MPPT control under partial shading condition, "2016 IEEE 8th International Power Electronics and Motion Control Conference (IPEMC-ECCE Asia), Hefei, 2016, pp. 928-932.

[2] K. L. Lian, J. H. Jhang and I. S. Tian, "A Maximum Power Point Tracking Method Based on Perturb-and-Observe Combined With Particle Swarm Optimization, "in IEEE Journal of Photovoltaics, vol. 4, no. 2, pp. 626-633, March 2014.

[3] N. Khaldi, H. Mahmoudi, M. Zazi and Y. Barradi, "The MPPT control of PV system by using neural networks based on Newton Raphson method," 2014 International Renewable and Sustainable Energy Conference (IRSEC), Ouarzazate, 2014, pp. 19-24.

[4] H. Renaudineau et al., "A PSO-Based Global MPPT Technique for Distributed PV Power Generation," in IEEE Transactions on Industrial Electronics, vol. 62, no. 2, pp. 1047-1058, Feb. 2015.

[5] X. Liu and L. A. C. Lopes, "An improved perturbation and observation maximum power point tracking algorithm for PV arrays, "2004 IEEE 35th Annual Power Electronics Specialists Conference (IEEE Cat. No.04CH37551), 2004, pp. 2005-2010 Vol. 3.

[6] Y. Ma, T. Bai, X. Zhou and Z. Gao, "Summary of photo voltaic and maximum power point tracking," 2017 29th Chinese Control And Decision Conference (CCDC), Chongqing, 2017, pp. 2298-2303.

[7] K. Ding, X. Bian, H. Liu and T. Peng, "A MATLAB-Simulink-Based PV Module Model and Its Application Under Conditions of Nonuniform Irradiance, " in IEEE Transactions on Energy Conversion, vol. 27, no. 4, pp. 864-872, Dec. 2012. 
[8] M. Azab, "A New Maximum Power Point Tracking for Photovoltaic Systems," WASET, vol. 34, 2008, pp. 571-574.

[9] R. Sankarganesh and S. Thangavel, "Maximum power point tracking in PV system using intelligence based $\mathrm{P} \& \mathrm{O}$ technique and hybrid cuk converter," 2012 International Conference on Emerging Trends in Science, Engineering and Technology (INCOSET), Tiruchirappalli, Tamilnadu, India, 2012, pp. 429-436.
[10] M. W. Rahman, C. Bathina, V. Karthikeyan and R. Prasanth, "Comparative analysis of developed incremental conductance (IC) and perturb \& observe (P\&O) MPPT algorithm for photovoltaic applications, "2016 10th International Conference on Intelligent Systems and Control (ISCO), Coimbatore, 2016, pp. 1-6. 